\title{
Erratum to: Ventilator-associated pneumonia: current status and future recommendations
}

\author{
Shai Efrati • Israel Deutsch • Massimo Antonelli • \\ Peter M. Hockey $\cdot$ Ronen Rozenblum • \\ Gabriel M. Gurman
}

Published online: 21 June 2012

(C) Springer Science+Business Media, LLC 2012

\section{Erratum to: J Clin Monit Comput (2010) 24:161-168 DOI 10.1007/s10877-010-9228-2}

The authors regret that text from the article entitled "Implementing Quality in Improvements in the Intensive Care Unit: Ventilator Bundle as an Example" written by Marya D. Zilberberg, Andrew F. Shorr, Marin H. Kollef and published in Critical Care Medicine 37, 305-309
(2009) was copied in the original publication of the article published in J Clin Monit Comput on 2010 Apr; 24(2): $161-8$.

The proper course of action would have been to cite $\mathrm{Dr}$ Zilberberg's text in appropriate quotational form, and include Dr. Zilberberg et al. article to the reference list. We deeply apologize for this mistake.

The online version of the original article can be found under doi:10.1007/s10877-010-9228-2.

S. Efrati $(\bowtie) \cdot$ I. Deutsch

Research \& Development Unit, Assaf Harofeh Medical Center, Affiliated with the Sackler School of Medicine, Tel-Aviv University, Zerifin 70300, Israel

e-mail: efratishai@013.net

M. Antonelli

Department of Intensive Care and Anesthesiology, Policlinico Universitario A. Gemelli, Università Cattolica del Sacro Cuore, Largo A, Rome, Italy

P. M. Hockey

General and Respiratory Medicine, Hampshire Community

Health Care, Hampshire, UK

R. Rozenblum

The Center for Patient Safety Research and Practice, Division of General Medicine, Brigham \& Women's Hospital and Harvard

Medical School, Boston, MA, USA

G. M. Gurman

Faculty of Health Sciences, Beer-Sheva, and Myney Hayesuah Medical Center, Ben-Gurion University of the Negev, Bnei

Brak, Israel 